\title{
EFFECTIVE COMPOSITES EMPLOYING FAST- HARDENING GYPSUM CEMENT BINDERS FOR ADDITIVE MANUFACTURING
}

\author{
Natalia Vasilyevna Chernysheva \\ Institute of Architecture and Construction \\ Belgorod State Technological University named after \\ V.G. Shoukhov \\ Belgorod, Russia \\ naukavs@mail.ru \\ Valery Stanislavovich Lesovik \\ Institute of Architecture and Construction \\ Belgorod State Technological University named after \\ V.G. Shoukhov \\ Belgorod, Russia \\ naukavs@mail.ru
}

\author{
Evgeny Sergeyevich Glagolev \\ Institute of Architecture and Construction \\ Belgorod State Technological University named after \\ V.G. Shoukhov \\ Belgorod, Russia \\ naukavs@mail.ru
}

\author{
Aleksandr Anatolevich Volodchenko \\ Institute of Architecture and Construction \\ Belgorod State Technological University named after \\ V.G. Shoukhov \\ Belgorod, Russia \\ naukavs@mail.ru
}

\author{
Maria Yurievna Drebezgova \\ Institute of Architecture and Construction \\ Belgorod State Technological University named after V.G. Shoukhov \\ Belgorod, Russia \\ naukavs@mail.ru
}

\begin{abstract}
Currently, development and implementation of new technologies has come to the fore in every field of industrial production. Interest to additive manufacturing grows in Russia and abroad, including application of such technologies in architecture and construction, allowing production of forms and structures with previously unattainable forms and complexity layer-by-layer. To this end, the authors propose using a new generation of waterproof and frost-proof gypsum-based composite binders with fine-milled mineral additives of diverse genesis, including a unique additive previously unknown to be used in construction material science, namely mining waste from wet magnetic separation of jaspilite, which significantly differs from traditional quartz raw material. Due to their specific composition and morphology, wet magnetic separation waste in gypsum cement mixtures gives a significant increase in strength (up to $30 \mathrm{MPa}$ ), water resistance (up to 0.8 ) and frost-proofness.
\end{abstract}

Keywords-3D-technologies, additive manufacturing, composite gypsum binders, mineral additive, construction composite.

\section{INTRODUCTION}

Currently, development and implementation of new technologies has come to the fore in every field of industrial production. Interest to additive manufacturing grows in Russia and abroad, including use of such technologies in architecture and construction [1-4].

Concrete printing technology, so-called Additive Layered Manufacturing (ALM), is very young: it was first employed in China in 2014. Recently architects and builders alike have more often turned to 3D-printing technologies, which allow fast construction of buildings and maximizing labor saving. It is an ideal technology for construction jobs and low-rise development, when it is necessary to construct one or two buildings with certain complex architectural features, which may be impossible to implement using the standard methods of construction. Traditional technologies and forms have an advantage when a whole series of buildings is produced, including thousands and tens of thousands of uniform components.

Development of technology and equipment for 3D additive technologies continues worldwide; however, there is currently no scientific justification of what kind of construction composite materials, technologies and rules shall be used to create it. The information on types of concrete meeting all the current requirements for 3D printing technologies are scarce.

\section{METHODS}

An effective method to improve performance characteristics of construction materials on the basis of gypsum binders lies in resolving its combination with portland cement and silica-containing additives of a certain genesis into an integral composition, thus obtaining control of stable structure formation in joint hardening. Without resolving this important issue, creation of durable materials on the basis of gypsum binders is impossible. For several decades, the mechanisms of hardening and destruction of mixed gypsum cement composition has being been studied by many material science researchers; however, the information available is contradictory, hard to compare, non-systemic and lacking 
criteria for design of such binders which creates obstacles for their production. Possibility of use of new silica-containing mineral additives is understudied; the same may be said about influence of genesis and properties of quartz-containing raw material on the structure formation processes in composite gypsum binder (CGB). Creation of multi-component systems by modification of existing binders with considerations for genetic properties of quartz-containing components coming from technogenic and natural sources in combination with other additives, studies of its structure and ways to influence it will allow obtaining high-quality construction composites characterized by increased water resistance and durability.

To study the influence of different silica-containing mineral additives, natural and man-made raw materials of diverse chemical composition taken from different occurrences in the territory of Russia, CIS countries and Middle East were used, while taking into account influence of their genesis onto the structure formation in a complex system "gypsum - cement - mineral additive - superplasticizer water". Different rocks were used as sources of the mineral additives.

An effective method to improve performance characteristics of construction materials on the basis of gypsum binders lies in resolving its combination with portland cement and silica-containing additives of a certain genesis into an integral composition, thus obtaining control of stable structure formation in joint hardening. Without resolving this important issue, creation of durable materials on the basis of gypsum binders is impossible. For several decades the mechanisms of hardening and destruction of mixed gypsum cement composition has being been studied by many material science researchers, however, the information available is contradictory, hard to compare, non-systemic and lacking criteria for design of such binders which creates obstacles for their production. Possibility of use of new silica-containing mineral additives is understudied; the same may be said about influence of genesis and properties of quartz-containing raw material on the structure formation processes in composite gypsum binder (CGB). Creation of multi-component systems by modification of existing binders with considerations for genetic properties of quartz-containing components coming from technogenic and natural sources in combination with other additives, studies of its structure and ways to influence it will allow obtaining high-quality construction composites characterized by increased water resistance and durability.

To study the influence of different silica-containing mineral additives, natural and man-made raw materials of diverse chemical composition taken from different occurrences in the territory of Russia, CIS countries and Middle East were used, while taking into account influence of their genesis onto the structure formation in a complex system "gypsum - cement - mineral additive - superplasticizer water". Different rocks were used as sources of the mineral additives.

\section{MAIN PART}

Modern trends in development of construction material science are defined by shift to creation of multi-component, multi-layered, multi-level composite materials with a predefined set of properties, understanding their structural and functional organization. It ensures their behavior being adapted to variable factors of environment throughout their useful life in addition to minimum requirements of preservation or improvement of the environmental quality. The available scientific and technical research in the field of gypsum binders, as both materials and products, during the last 50 years, as well as advantageous technical and economic aspects of production and application of materials and products on its base, highlight the unmet needs for wide application in both traditional and modern methods of construction and reconstruction. Due to that there is a need for development of fast-hardening construction composites manufactured from new easily-available raw materials with enhanced performance characteristics. Water resistant and frost-proof gypsum composites fully meet these requirements; their use will allow not only to reduce existing deficit of walling materials, but in many cases to replace energyconsuming cement concretes and significantly reduce time required for construction of buildings and structures.

Additive manufacturing or ALM are among the most dynamic modern trends in today's science. In a relatively short period of time from appearance of the first 3D printer we are now able to print plates and dishes, toys, machinery and even human organs and tissues. A range of items available for $3 \mathrm{D}$ printing is constantly extending.

Principles of layered synthesis were first formulated in the second half of the 20th century; however, only recently 3D additive manufacturing has begun conquering the industrial sector. The industry is the most sought-after and actively developed trend in the 3D additive manufacturing. For instance, there are already examples of houses printed and being used for their purpose in China. Several dozens of houses were erected during a day with the help of a 3D printing technology. A unique plant, consisting of four 3D printers with a width of 10 meters and a height of 6.6 meters, is used to print houses; it uses a mixture of cement and mining wastes as a construction material.

To improve the efficiency of the ALM technology, it is necessary to create special types of concrete on the basis of inexpensive and commonly available construction materials with fast hardening that create comfortable human environment. Quartz-containing rocks of diverse genesis may be used to obtain such materials.

A fast-hardening reactive powder concrete, reinforced with steel and polymer microfibers, is proposed for that purpose; its feature is absence of coarse aggregate without loss in a binder/solid rate, as well as very high performance indicators (concrete of Grade B60 and higher). Sand concretes using reaction powder binder have a high factor of constructive quality, allowing creation of structures with lower volume compared to regular structures and as a result, with lower weight and reduced consumption of materials. 
Less expensive fine aggregate and sand concretes modified with organic additives (superplasticizers, accelerating agents, mineral fiber), as well as clay mortar, may be used for fast construction of affordable housing with the help of $3 \mathrm{D}$ printing technologies. Innovative woven threedimensional meshed frames may be used as reinforcement. Ceramic concrete with its unique characteristics of fire resistance and thermal conductivity is a highly promising material for manufacturing of complex items.

In Belgorod State Technical University named after V.G. Shoukhov in the Department of Construction Materials Science, Products and Structures under supervision of Professor V.S. Lesovik, Doctor of Engineering, Professor N.V. Chernysheva, Doctor of Engineering researcher are working on a new transdisciplinary line of research - geonics (geomimetics) - that serves as a theoretic foundation of construction material science, actively developing a theory of design and synthesis of smart gypsum composite materials with regularized structure for the future of the construction industry, including ALM. Such properties will allow for shortening of time period required for construction, reduction of environmental impact in comparison to traditionally used portland cement [14-15].

Advantages of such materials (low cost, environmental compatibility, fast strength gain, good thermal and acoustic insulation, absence of shrinking deformations, fire resistance, positive influence on human comfort by creation of advantageous microclimate etc) allow keeping and improving functional performance of buildings and comfort of their internal environment (Table 1).

TABLE I. ENVIRONMENTAL ASPECT OF MINERAL BINDERS MANUFACTURE

\begin{tabular}{|c|c|c|c|c|c|c|c|}
\hline \multirow{3}{*}{ 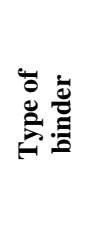 } & \multirow{3}{*}{ 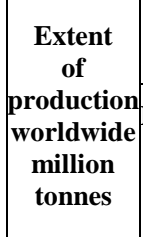 } & \multicolumn{2}{|c|}{$\begin{array}{c}\text { Energy capacity, } \\
\text { kgoe }\end{array}$} & \multicolumn{4}{|c|}{ Environmental characteristics } \\
\hline & & \multirow{2}{*}{$\begin{array}{c}\text { Manufacture } \\
\text { kgoe per } \\
\text { tonne } \\
.\end{array}$} & \multirow{2}{*}{$\begin{array}{c}\text { Total } \\
\text { million } \\
\text { tonnes } \\
.\end{array}$} & \multicolumn{2}{|c|}{$\mathrm{CO} 2$} & \multicolumn{2}{|c|}{ fines } \\
\hline & & & & $\mathrm{kg} /$ tonne & $\begin{array}{c}\text { Total } \\
\text { million } \\
\text { tonnes }\end{array}$ & $\mathrm{kg} / \mathrm{t}$ & $\begin{array}{c}\text { Total } \\
\text { emillion } \\
\text { tonnes }\end{array}$ \\
\hline Cement & 3700 & 150 & 555 & 50 & 2159 & 21 & 53.34 \\
\hline Lime & 3 & 204 & 69.36 & 28 & 151 & 5 & 1.43 \\
\hline Gypsum & 152 & 47 & 7.144 & - & - & - & - \\
\hline & Total & & & & 2310 & & 54.77 \\
\hline
\end{tabular}

Additionally, fast hardening of gypsum allows sparing significant energy costs currently spent for thermal treatment to produce a diverse range of products, thus reducing their production energy costs (Table 2).

The world practice shows a radical growth in production of construction materials on the basis of water-resistant CGB. Common usage of gypsum materials is especially important for Russia, because a half of proven gypsum deposits are within its territory. Unlimited supply of gypsum-containing and silica-containing technogenic raw materials in the Russian Federation facilitates profitability of CGB-based composites.
TABLE II. COMPARISON OF PRODUCTION ENERGY COSTS OF DIFFERENT BINDERS

\begin{tabular}{|c|c|}
\hline Type of binder & Energy costs, \% \\
\hline Portland Cement & 100 \\
\hline Anhydrous lime & 95 \\
\hline Slaked lime & 75 \\
\hline Gypsum binder & 2 \\
\hline Anhydrous gypsum binder & 10 \\
\hline
\end{tabular}

Common usage of gypsum materials is especially important for Russia, because a half of world has proven that gypsum deposits are within its territory. Unlimited supply of gypsum-containing and silica-containing technogenic raw materials in the Russian Federation facilitates profitability of CGB-based composites.

Construction 3D printer uses extrusion technology (3D extrusion), where each new layer of a construction material is pressed out of the printer on top of the previous one following a preprogrammed contour, thus allowing growth of walling of practically any form imaginable (Fig. 1).

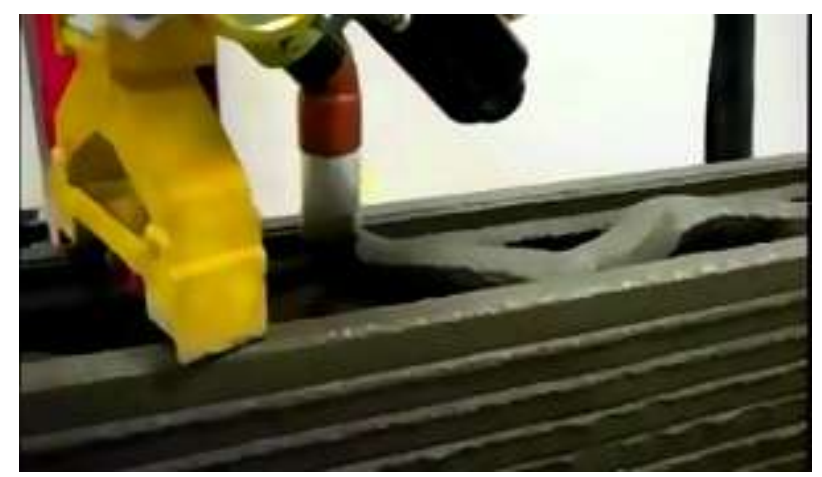

Fig. 1. Rising of a wall by extrusion of a concrete mixture from an operating nozzle on top of a previously extruded layer

This technology is called FDM (Fused Deposition Modeling). Generally, the 3D printer prints the outer shell of the structure (nonremovable casing) out of special types of construction materials with a special set of requirements: they shall keep their geometry after the die despite internal stresses and gravity; they shall be fast hardening and fast maturing to be able to support the succeeding layers; they shall have a certain level of water resistance [5-11]. Thickness of the layer applied in a single operation shall be about $5-8 \mathrm{~cm}$. Thicker layers may lead to dulling. Application of the succeeding concrete layers depends on its hardening rate, defined by ambient temperature, type of binder, presence of additives (accelerators and plasticizers). That means, that the concrete (composite) mix proportions shall be designed in such a way that it is fast to harden and does not dull, so that the top levels do not ruin the lower levels. Thus, to creation of a composite with the necessary properties requires finding links between different feed components forming the composite or its contact layer. It is viable to apply some experience taken from geological processes. What is meant here is a genesis of a wide range of anisotropic rocks (banded, foliated structures etc), where the anisotropy coefficient may go as low as $2 \ldots 3$, 
unlike $5 \ldots 7$ or higher, characteristic of man-made layered structures.

There is a range of construction composites developed on the basis of fast hardening water resistant gypsum binder (CGB), modified with a diverse range of additives - mineral aggregates, superplasticizers, hyperplasticizers and cure retarders - able to provide control and regulation of structure formation in plastic state and during the formation of the structural strength of the composites. High-dispersive aggregates obtained by fine grinding of technogenic (mining waste from wet magnetic separation of jaspilite, sieve residue from quartzy sandstone, concrete breakage) and natural (quartz sand, gaize, perlite, tuff) raw materials facilitate effective control of internal structure formation of composites thus providing high quality of products on their basis. At that, specific surface area of the milled mineral additives shall exceed $500 \ldots 600 \mathrm{~m}^{2} / \mathrm{kg}$.

A CGB production technology is proposed that includes several stages and provides improvement of morphology and surface characteristics of the particles, high hydration of clinker component and increased activity of silica, allowing to a certain degree to control the ettringite formation process.

The 1st stage is preparatory, depending on the mineral additive used and includes trommelling, fragmentation and drying operations;

The 2nd stage is preparation of the hydraulic component, a fine mixture of portland cement with an active mineral additive (superplasticizer);

The 3rd stage is mixing of the gypsum binder with the hydraulic component combined with a short-term grinding.

Grain size analysis shows that the binder developed has a polymodal distribution showing an elevated level of fine particles with a distinct maximum at $0.5 \ldots 2.46$ micron range, such particles improve microstructure formation of the gypsum cement stone and facilitate the densest packing of the CGB grains (Figure 2).

Experience has shown that there is a ratio of portland cement and fine-milled mineral additives that provides optimal conditions for hardening of the binder (as per TU 21-31-62-89 Gypsum Cement Puzzolanic Binder).

To obtain non-flaking CGB-based concrete mixtures for application in ALM technologies for production of highdensity reinforcement and thin-walled concrete products and structures, a number of complex super- and hyperplasticizersbased chemical additives, as well as cure retarders, are able to provide possibility to regulate and control structure formation in a plastic state and during the formation of the structural strength of the composites.

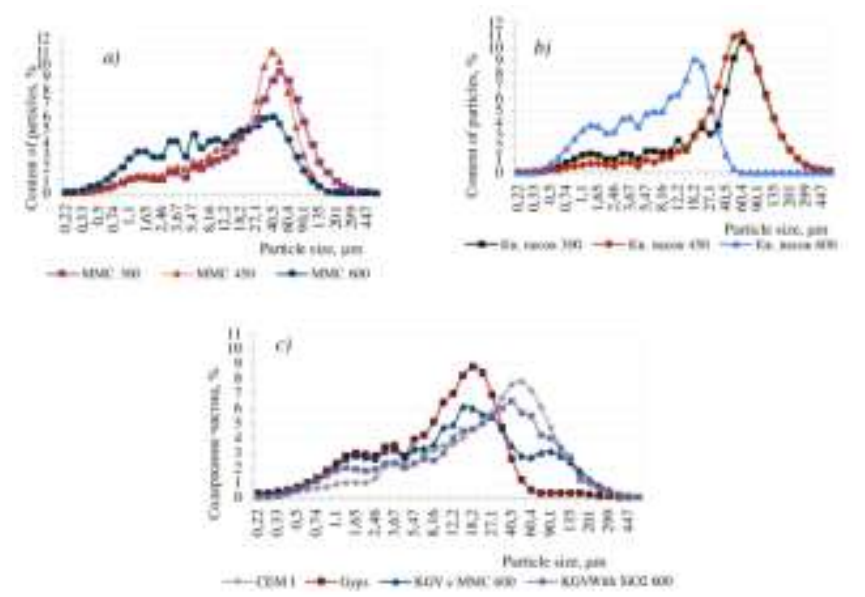

Fig. 2. Grain size distribution of CGB and its components: $a$ - WMS waste; $b$ - quartz sand; $c$ - Gypsum, protland cement and CGB

A characteristic grain sizing of fine-milled WMS waste (presence of all particle sizes with several well-defined peaks) significantly differs from that of the quartz sand due to polygenic nature of the rock-forming mineral, quartz (Table $3)$.

At that, with increased specific surface area of the WMS waste, activity of the CGB does not significantly change (compared to quartz sand), because the mineral additive itself is quite active to begin with.

TABLE III. IMPACT OF MINERAL ADDITIVE SURFACE AREA ONTO THE CGB $*$ PROPERTIES (WATER BINDER RATIO $=0.5$ )

\begin{tabular}{|c|c|c|c|c|c|c|c|c|c|}
\hline \multirow[t]{2}{*}{$\begin{array}{l}\text { Type of } \\
\text { mineral } \\
\text { additive }\end{array}$} & \multirow{2}{*}{$\begin{array}{c}\text { Specific } \\
\text { surface } \\
\text { area } \\
\text { of the } \\
\text { mineral } \\
\text { additive } \\
\mathbf{m}^{2} / \mathbf{k g}\end{array}$} & \multirow{2}{*}{ 粍 } & \multicolumn{2}{|c|}{$\begin{array}{l}\text { Hardening } \\
\text { period } \\
\text { min-sec }\end{array}$} & \multicolumn{4}{|c|}{$\begin{array}{c}\text { Compressive } \\
\text { strength, MPa, on } \\
\text { term }\end{array}$} & \multirow[t]{2}{*}{$\begin{array}{c}\text { Softening } \\
\text { coefficient, } \\
\text { Cs }\end{array}$} \\
\hline & & & start & end & $2 \mathrm{~h}$ & $7 \mathrm{~d}$ & $\begin{array}{c}28 \\
\text { d }\end{array}$ & dry & \\
\hline \multirow{3}{*}{$\begin{array}{l}\text { WMS } \\
\text { waste }\end{array}$} & 300 & \begin{tabular}{|l|l|}
0.190 \\
\end{tabular} & $9-30$ & $\begin{array}{l}12- \\
30\end{array}$ & 5.1 & \begin{tabular}{|l|}
12.2 \\
\end{tabular} & 15.2 & 20.5 & 0.72 \\
\hline & 450 & \begin{tabular}{|l|l|}
0.180 \\
\end{tabular} & $9-00$ & $\begin{array}{l}12- \\
00\end{array}$ & 5.3 & 12.6 & 15.6 & 21.6 & 0.74 \\
\hline & 600 & 0.175 & $9-00$ & $\begin{array}{l}12- \\
00\end{array}$ & 5.5 & 12.8 & 16.8 & 22.0 & 0.78 \\
\hline \multirow{3}{*}{$\begin{array}{l}\text { Silica } \\
\text { sand }\end{array}$} & 300 & 0.155 & $4-50$ & $8-26$ & 4.2 & \begin{tabular}{|l|}
8.9 \\
\end{tabular} & 9.3 & 18.5 & 0.71 \\
\hline & 450 & 0.150 & 4-47 & $9-30$ & 5.7 & 10.8 & 12.4 & 19.6 & 0.73 \\
\hline & 600 & 0.144 & $4-47$ & $\begin{array}{l}10- \\
33\end{array}$ & 7.3 & 13.1 & 14.0 & 20.1 & 0.75 \\
\hline
\end{tabular}

That is why, the use of WMS waste from enrichment of metamorphic rocks of green schist facies as an active mineral additive in CGB production is especially effective in comparison to sedimentary quartz sand. Let us note that the highest Kp value of $0.78-0.81$ is demonstrated by CGB with WMS waste, thus vividly showing a difference between a regular quartz and an active one (Table 4. 
TABLE IV. ACTIVITY INDICATORS OF HARDENED GYPSUM BINDER AND CGB

\begin{tabular}{|c|c|c|c|c|c|c|c|c|c|c|c|c|c|c|}
\hline \multirow[t]{2}{*}{ No. } & \multirow[t]{2}{*}{$\begin{array}{c}\text { Conditions } \\
\text { of hardening }\end{array}$} & \multicolumn{3}{|c|}{ Composition, \% wt. } & \multicolumn{5}{|c|}{$\begin{array}{c}\text { Compressive strength, MPa, } \\
\text { after } 24 \text { hours }\end{array}$} & \multicolumn{5}{|c|}{$\begin{array}{l}\text { Softening coefficient, } \\
\text { after } 24 \text { hours }\end{array}$} \\
\hline & & $\mathbf{G}$ & $\mathbf{C}$ & MA & 28 & 90 & 180 & 360 & 2 years & 28 & 90 & 180 & 360 & 2 years \\
\hline \multicolumn{15}{|c|}{ Gypsum binder } \\
\hline 1 & $\begin{array}{c}\text { In air } \\
\text { In water }\end{array}$ & 0 & - & - & $\begin{array}{r}18.3 \\
6.0 \\
\end{array}$ & $\begin{array}{r}18.3 \\
4.4 \\
\end{array}$ & $\begin{array}{r}18.5 \\
3.9 \\
\end{array}$ & $\begin{array}{r}17.8 \\
2.8\end{array}$ & $\begin{array}{r}16.4 \\
1.9 \\
\end{array}$ & $\begin{array}{c}0.34 \\
- \\
\end{array}$ & $\begin{array}{c}0.33 \\
- \\
\end{array}$ & $\begin{array}{c}0.33 \\
- \\
\end{array}$ & $\begin{array}{c}0.32 \\
- \\
\end{array}$ & $\begin{array}{c}0.31 \\
- \\
\end{array}$ \\
\hline \multicolumn{15}{|c|}{ CGB with WMS waste } \\
\hline 3 & $\begin{array}{c}\text { In air } \\
\text { In water }\end{array}$ & $r n$ & $-n$ & $-n$ & $\begin{array}{l}17.0 \\
13.1 \\
\end{array}$ & $\begin{array}{l}17.4 \\
13.4 \\
\end{array}$ & $\begin{array}{l}17.6 \\
14.1 \\
\end{array}$ & $\begin{array}{l}17.6 \\
14.2 \\
\end{array}$ & $\begin{array}{l}17.8 \\
14.3 \\
\end{array}$ & $\begin{array}{c}0.78 \\
- \\
\end{array}$ & $\begin{array}{c}0.79 \\
- \\
\end{array}$ & $\begin{array}{c}0.80 \\
- \\
\end{array}$ & $\begin{array}{c}0.80 \\
- \\
\end{array}$ & $\begin{array}{c}0.81 \\
- \\
\end{array}$ \\
\hline \multicolumn{15}{|c|}{ CGB with quartz sand } \\
\hline 4 & $\begin{array}{c}\text { In air } \\
\text { In water }\end{array}$ & $1-0$ & $-n$ & $-n$ & $\begin{array}{c}13.0 \\
9.8 \\
\end{array}$ & $\begin{array}{l}13.4 \\
10.2 \\
\end{array}$ & $\begin{array}{l}13.8 \\
10.6 \\
\end{array}$ & $\begin{array}{l}13.9 \\
10.6 \\
\end{array}$ & $\begin{array}{c}13.9 \\
- \\
\end{array}$ & $\begin{array}{c}0.75 \\
- \\
\end{array}$ & $\begin{array}{c}0.76 \\
- \\
\end{array}$ & $\begin{array}{c}0.77 \\
- \\
\end{array}$ & $\begin{array}{c}0.78 \\
- \\
\end{array}$ & $\begin{array}{c}0.78 \\
- \\
\end{array}$ \\
\hline
\end{tabular}

Mineral additives in the CGB composition take active part in the hydration process. Increased strength during the hardening is defined by CGB composition and unfolds in parallel to changes in their microstructure and phase composition of new structures.

The principle cementing substances in the studied samples of CGB with WMS waste (as the most effective mineral additive) are: calcium sulfate dihydrate $(\mathrm{d}=7,62 ; 4,28$; $3,81 \ldots \AA)$, calcium carbonate $(\mathrm{d}=2,502 ; 2,088 ; 1,89 \ldots \AA)$, quartz $(\mathrm{d}=3,34 ; 1,54 \ldots \AA)$, partially crystalline tobermoritelike calcium hydrosilicate $(\mathrm{d}=11,3 ; 5,00 ; 3,07 ; 2,87 ; 2,79$; $2,41 ; 1.99 ; 1.84 ; 1,81 \ldots \AA)$, traces of portland cement $(\mathrm{d}=2,73$; $1,95 ; 1,93 ; 1,78 \ldots \AA)$, traces of ettringite $(\mathrm{d}=5.6 ; 4.92 \ldots \AA)$.

The process of formation of a common matrix may be activated by means of nucleating agents; this role may be performed by floured calcium sulfate dihydrate for gypsum and by floured concrete wastes (Table 5).

TABLE V. PROPERTIES OF CGB (WATER BINDER RATIO =0,5)

\begin{tabular}{|c|c|c|c|c|c|c|c|c|}
\hline \multirow[t]{2}{*}{$\begin{array}{c}\text { Type of } \\
\text { mineral additive }\end{array}$} & \multirow[t]{2}{*}{$\begin{array}{c}\text { Fluidity } \\
\text { m }\end{array}$} & \multicolumn{2}{|c|}{$\begin{array}{l}\text { Hardening } \\
\text { period } \\
\text { min-sec }\end{array}$} & \multicolumn{4}{|c|}{$\begin{array}{c}\text { Compressive } \\
\text { strength, MPa, on } \\
\text { term }\end{array}$} & \multirow[t]{2}{*}{$\begin{array}{c}\text { Softening } \\
\text { coefficient } \\
\text { Cs }\end{array}$} \\
\hline & & start & end & $2 \mathrm{~h}$ & $7 \mathrm{~d}$ & $28 \mathrm{~d}$ & dry & \\
\hline WMS waste & 0.175 & $9-00$ & $12-00$ & 5.5 & 12.8 & 16.8 & 22.0 & 0.78 \\
\hline Quartz sand & 0.144 & $4-47$ & $10-33$ & 7.3 & 13.1 & 14.0 & 20.1 & 0.75 \\
\hline Quartzy sandstone* & 0.180 & $8-30$ & $11-30$ & 3.7 & 10.1 & 15.6 & 21.3 & 0.75 \\
\hline Concrete waste ${ }^{* *}$ & 0.120 & $8-00$ & $9-30$ & 4.2 & 17.4 & 28.3 & 31.0 & 0.62 \\
\hline Chamotte fines & 0.160 & $7-00$ & $9-00$ & 4.5 & 6.5 & 10.4 & 17.3 & 0.62 \\
\hline Gaize & 0.110 & $3-00$ & $5-00$ & 7.0 & 8.2 & 10.8 & 17.6 & 0.43 \\
\hline Perlite & 0.115 & $4-00$ & $5-30$ & 7.5 & 9.0 & 12.1 & 18.1 & 0.44 \\
\hline
\end{tabular}

At the opening stage, the fast strengthening of the system is achieved due to synthesis of large crystals of calcium sulfate dihydrate which simultaneously performs the function of controlled early curing (Fig. 3, a).

Then in the previously created structure, as a result of hydration of clinker minerals, a new structure is formed by crystallization of nano and micro level low-basic calcium hydrosilicates that makes the structure denser; this new structure depends on genetic features of silica in the mineral additives and provides additional strength and water resistance to the hardened gypsum cement stone (Fig. 3).

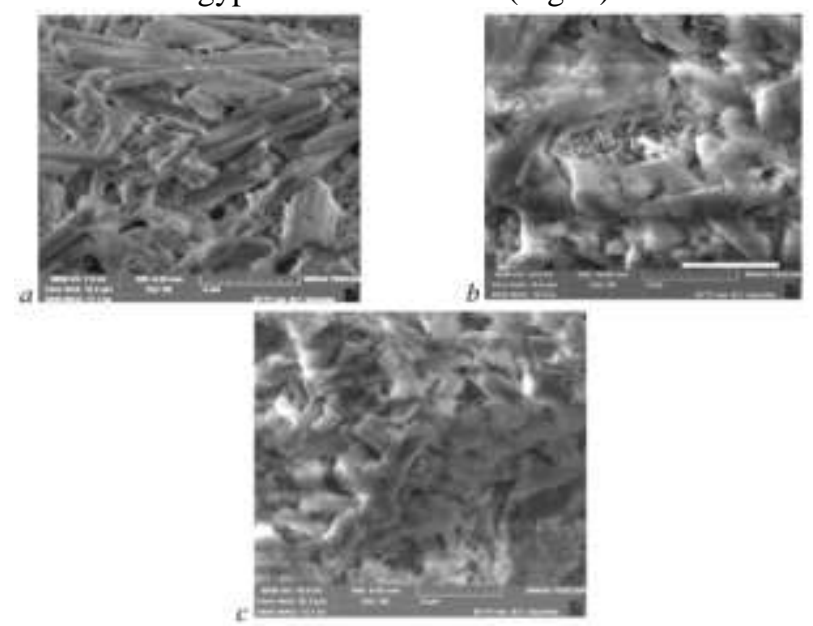

Fig. 3. Microscopic structure of hardened CGB: a - after 2 hours; b - after 7 days; c - after 28 days

Threadlike formations of diverse morphology and size (with a length from 1 to 20 micron and width under 0.01 micron, generally from 20 to $60 \mathrm{~nm}$ ) appear in the common gel. The further crystallization of previously formed objects facilitates self-packing of the system of diverse morphogenetic types of nano and microscale crystalline formations, which form had been determined previously at stage two (precrystallization).

At the third stage, there is second-generation new growths of calcium hydrosilicates by means of reaction between the portlandite (appearing from hydration of alite) and active X-ray amorphous particles of mineral additives with the further self-organization, thus providing final strength and water resistance of the material.

This mechanism of CGB hydration minimizes internal stress and bulk strain, thus reducing the number of hairline cracks and increasing the effectiveness of the CGB obtained in comparison with the traditional gypsum binder. The pores become almost completely overgrown with small calcium 
hydrosilicate crystals that serve as reinforcement and create an integral dense mesh-like structure around the gypsum crystals that looks like several meshes penetrating each other, thus increasing gel porosity and significantly increasing strength and water resistance of the composites.

An average size of the disperse structure particle was calculated from a small-angle X-ray pattern and was found to be $35 \mathrm{~nm}$.

All the phase transitions of calcium sulfate happen in the area of maximum concentration of positively charged sorption centers

That is why the CGB design requires selecting such mineral additives that have an excess of negatively charged centers on their surface.

The further increase in quality of the CGB-based composites may be achieved by application of chemical additives to provide regulation and control of structure formation in their plastic state and during the formation of structural strength.

\section{SUMMARY}

Thus, due to their unique properties (environmental performance, fast hardening and maturing and others), the CGB developed may be used as a material in constructional 3D printing. Their application will allow curbing deficit of walling materials, in many cases replacing energy-costly cement concretes and significantly reducing the time required for construction of buildings and structures.

The following approaches to production of fine concrete are proposed: radiation and thermal activation of quartz sand with a beam of accelerated electrons at a temperature of 500$900{ }^{\circ} \mathrm{C}$ during 1 - 9 minutes, which allows one to activate its surface, change fractional composition, lower the sand's void ratio by $5.5 \%$ and increase the strength of the composite by $30-40 \%$. Another approach is low-energy activation of the fine concrete mixture on the basis of WMS waste with an external magnetic field, allowing one to increase the strength of cured fine concrete by $30-35 \%$.

From the mathematical models that link quality indicators of the material (hardening time, fluidity, compressive strength etc) with the composition of the concrete mixture, regularities in structure formation of the composites were discovered that allows designing gypsum materials with predefined properties.

Advantageous technical and economic evaluation of potential efficiency of water resistant gypsum composite materials was achieved by means of using local natural and technogenic raw materials, lowering the material costs, shorter construction time, and simplification of production technology.

\section{CONCLUSION}

Fundamentals of design and production of composite materials for additive manufacturing are a transition to transdisciplinary research, which are at the frontier today, including geonics (geomimetics).

Development of technology and equipment for 3D additive technologies continues worldwide, however, there is currently no scientific justification of such construction composite materials and technologies. Taking into account the evolution that the human environment currently undergoes, Russia is not ready to transfer to $3 \mathrm{D}$ technologies in construction sector yet.

This study resulted in scientific justification and development of principles for design of effective water resistant composites on the basis of CGB and production processes for their production for use in walling, road building and dry tender mix materials, including those for construction ALM.

An effective method to improve performance characteristics of construction materials on the basis of gypsum binders lies in resolving its combination with portland cement and silica-containing additives of a certain genesis into an integral composition, thus obtaining control of stable structure formation in joint hardening. Solution of this important issue is crucial for creation of durable materials on its basis

Such approaches, knowledge, methods were used during the creation of a new class of smart construction materials with effective properties [14-15].

\section{Acknowledgment}

The paper was prepared within the framework of development program of a foundational university on the basis of BSTU named after V.G. Shoukhov

\section{References}

[1] T. Wohlers, "Additivemanufacturingand 3D-printingstateoftheindustry: Annualworld-wideprogressreport”, Wohlers Associates, pp. 276, 2014

[2] S. Yang, YF Zhao, "Additive manufacturing-enabled design theory and methodology: a critical review", International Journal of Advanced Manufacturing Technology, №80(1-4) , pp. 327-342, 2015.

[3] WK Chiu, KM Yu, "Direct digital manufacturing of three-dimensional functionally graded material objects", Computer-Aided Design, №40(12), pp. 1080-1093, 2008

[4] S.H. Huang, P. Liu, A. Mokasdar, L. Hou, "Additive manufacturing and its societal impact: a literature review", International Journal of Advanced Manufacturing Technology, №67(5-8) , pp. 1191-1203, 2013.

[5] Y.W. Zhai, D.A Lados, J.L Lagoy, "Additive manufacturing: making imagination the major limitation,” JOM, №66(5) , pp. 808-816, 2014.

[6] D.R. Gress, R.V. Kalafsky, "Geographies of production in 3D theoretical and research implications stemming from additive manufacturing”, Geoforum, №60, pp. 43-52, 2015.

[7] B.N. Turner, S.A. Gold, "A review of melt extrusion additive manufacturing processes: II. Materials, dimensional accuracy, and surface roughness”, Rapid Prototyping Journal, №21(3) , pp. 250-261, 2015.

[8] Y. Huang, M.C. Leu, J. Mazumder, A. Donmez, "Additive manufacturing: current state, future potential, gaps and needs, and recommendations", Journal of Manufacturing Science and EngineeringTransactions of the ASME, №137(1), pp. 014001-1-014001-10, 2015.

[9] J. Deckers, J. Vleugels, J.P. Kruthl, "Additive manufacturing of ceramics: a review", Journal of Ceramic Science and Technology, №5(4) , pp. 245-260, 2014 .

[10] W.J. Chappell, C. Reilly, J. Halloran, LPB Katehi, "Ceramic synthetic substrates using solid freeform fabrication", IEEE Transactions on Microwave Theory and Techniques, №51(3), pp. 752-760, 2003. 
[11] H.H. Tang, H.C. Yen, "Slurry-based additive manufacturing of ceramic parts by selective laser burn-out", Journal of the European Ceramic Society, №35(3) , pp. 981-987, 2015.

[12] A.M. Watjen, P. Gingter, M. Kramer R. Telle, Novel prospects and possibilities in additive manufacturing of ceramics by means of direct inkjet printing. Advances in Mechanical Engineering, №6, pp. 141346, 2014.

[13] S. Adamczak, J. Bochnia, B. Kaczmarska, An analysis of tensile test results to assess the innovation risk for an additive manufacturing technology. Metrology and Measurement Systems, №22(1), pp. 127138, 2015.

[14] A.A. Volodchenko, V.S. Lesovik, A.N. Volodchenko, L.H. Zagorodnjuk, Improving the efficiency of wall materials for «green» building through the use of aluminosilicate raw materials. International Journal of Applied Engineering Research, №10(24), pp. 45142-45149, 2015.

[15] A.A. Kuprina, V.S. Lesovik, L.H. Zagorodnyk, M.Y. Elistratkin, Anisotropy of materials properties of natural and man-triggered origin. Research journal of applied sciences, №9(1), pp. 816-819, 2014. 